\title{
Quadricuspid Pulmonary Valve in a European Young Male Diagnosed by MRI
}

\author{
Romero-Reyes MJ ${ }^{1}$, Gonzalez $\mathrm{PG}^{2}$ and Heras $\mathrm{RP}^{1}{ }^{*}$ \\ 1Departamento de Cardiologia. Hospital Universitario Virgen de Valme, Spain \\ 2 Unidad de Imagen Cardiaca-ERESA. Hospital General Universitario, Spain
}

*Corresponding author: Rocio Picon, Departamento de Cardiologia, Hospital

Universitario Virgen de Valme, Spain, E-mail: rpiconh@hotmail.com

\begin{abstract}
Quadricuspid pulmonary valve is a rare congenital cardiac entity. Because of its usual asymptomatic course, it has been almost exclusively diagnosed after death or at cardiac surgery, and few cases have been documented in living patients by trans thoracic echocardiography or computed tomography, let alone by cardiac magnetic resonance imaging (MRI). We report the case of a young European male diagnosed with quadricuspid pulmonary valve detected on cardiac MRI.
\end{abstract}

Keywords: Quadricuspid pulmonary valve; Cardiac surgery; MRI; Pulmonary valves; Regurgitant fraction

Abbrevations: MRI: Magnetic Resonance Imaging; SSFP: Steady-State Free Precession; CT: Computed Tomography

\section{Case Report}

A 22 year-old-male with history of palpitations and a cardiac murmur since childhood and findings of mild to moderate pulmonic regurgitation secondary to pulmonary dysplasia on echo cardiogram, was referred for cardiac magnetic resonance (MRI). Steady-state free precession (SSFP) sequence images were obtained on the longitudinal planes of both ventricles showing normal volumes and biventricular systolic function (Figure 1).

A cross-sectional cine sequence at the pulmonary valve level showed a quadricuspid pulmonary valve with 3 equal-sized cusps and a rudimentary 4th cusp, with incomplete cusp coaptation (Figure 2) and a jet of mild pulmonary regurgitation. Velocity-encoded phase contrast images perpendicular to the pulmonary valve showed mild pulmonary regurgitation with a calculated regurgitant fraction of $13 \%$ (Figure 3 ). 


\section{Open Access Journal of Cardiology}

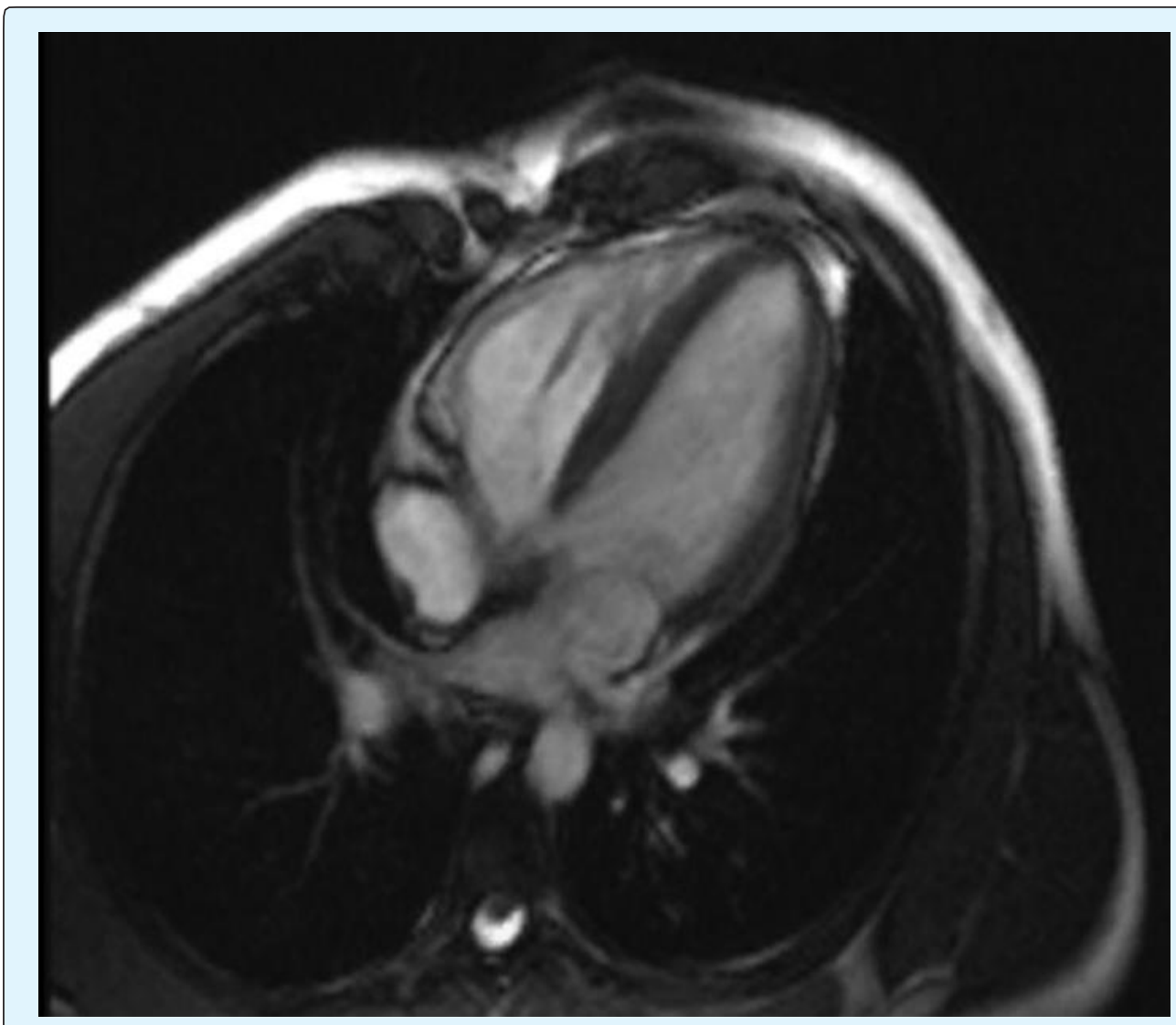

Figure 1: Cardiac magnetic resonance: SSFP cine acquisition in the four-chamber view. The image shows a right ventricle with normal volume.

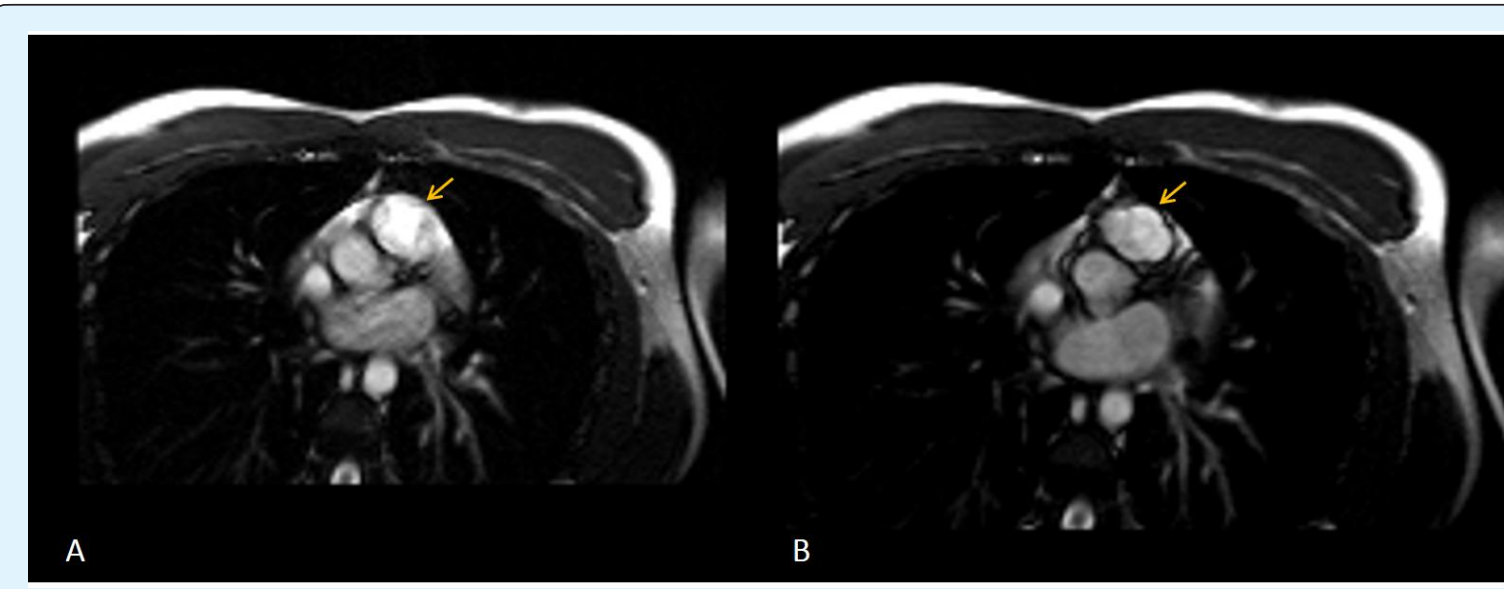

Figure 2: Cardiac magnetic resonance: SSFP cine acquisition in plane with pulmonary valve during sistole A: diastole B: The image shows a quadricuspid pulmonary valve causing an incomplete diastolic closure (arrows). 


\section{Open Access Journal of Cardiology}

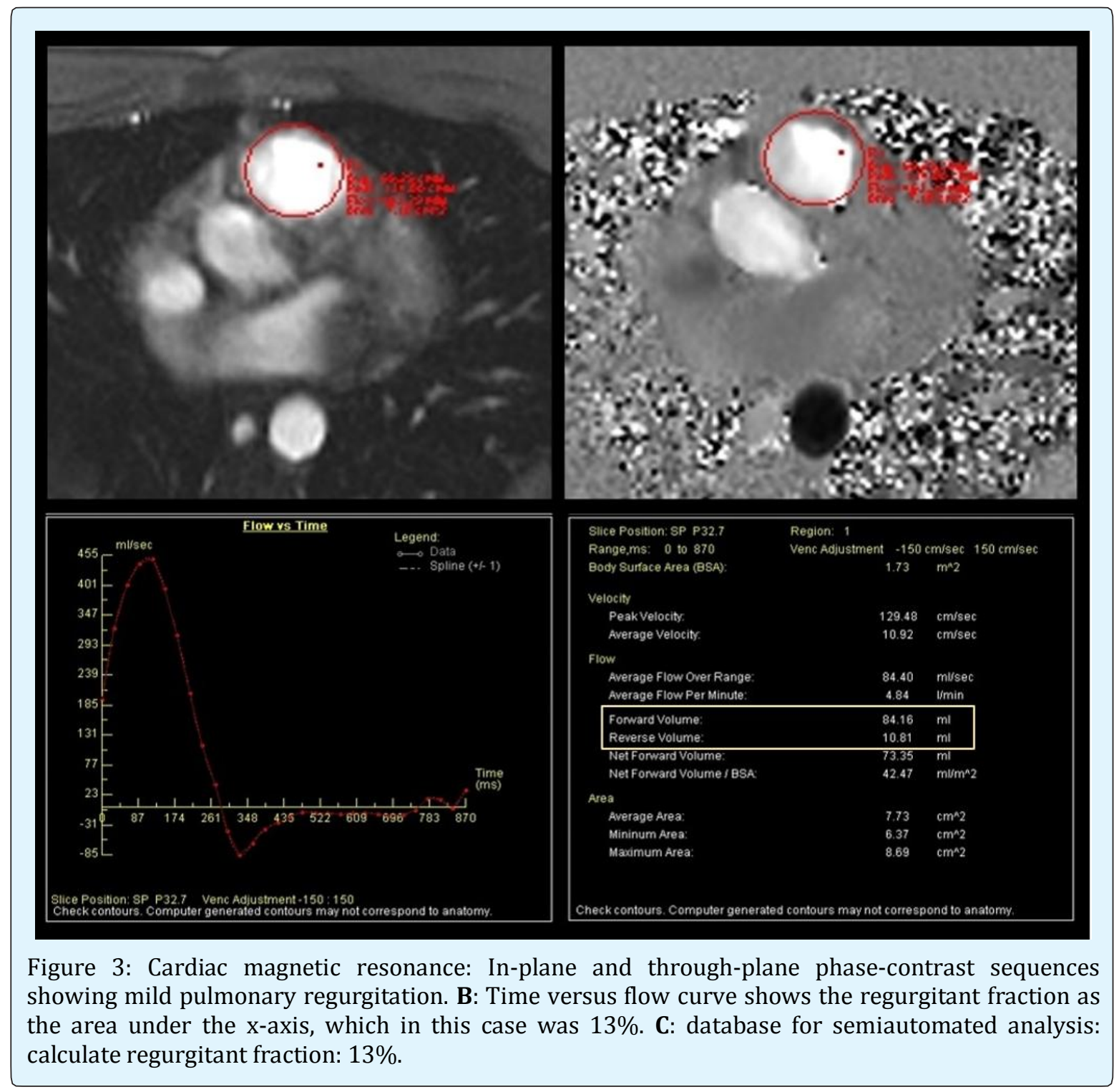

Quadricuspid pulmonary valve is a rare congenital cardiac entity. A prevalence of only $0.2 \%$ has been reported among donor hearts in the European Homograft bank [1]. It is more frequent among males and it is rarely associated with other congenital heart anomalies although it may sometimes coexist with patent ductus arteriosus, atrioventricular septal defects, and other anomalies [2]. While quadricuspid aortic valves can be associated with clinically significant dysfunction, quadricuspid pulmonary valves are rarely involve serious clinical complications and the incidence of abnormal function is is as low as 4\% [2]. For this reason, together the anatomical position of the pulmonary valve that typically only allows long-axis views of the pulmonary valve on trans thoracic echo cardiography, few cases of quadricuspid pulmonary valves have been reported, mainly as incidental discovery at surgery or during autopsy.

Cardiac imaging advances in the last decades have allowed more cases to be diagnosed in living patients, mainly by echocardiography or computed tomography (CT) [3] and only very few by cardiac MRI.

Although CT is an excellent technique with a high spatial resolution, cardiac MRI shows several advantages as it provides sufficient spatial and temporal resolution to define the number of leaflets and other anatomic problems and permits the accomplishment of dynamic studies with cine and velocity-encoded sequences which 


\section{Open Access Journal of Cardiology}

allow a complete assessment of the right ventricular structure and function and provide functional information of the pulmonary valve [4].

For this reason, cardiac MRI is a great imaging technique in the evaluation of pulmonary valve.

\section{References}

1. Jashari R, Van Hoeck B, Goffin Y, Vanderkelen A (2009) The incidence of congenital bicuspid or bileaflet and quadricuspid or quadrileaflet arterial valves in 3,861 donor hearts in the European Homograft Bank. J Heart Valve Dis 18(3): 337-344.
2. Davia JE, Fenoglio JJ, De Castro CM, McAllister HA, Cheitlin MD (1977) Quadricuspid semilunar valves. Chest 72(2): 186-189.

3. Akerem Khan SK, Anavekar NS, Araoz PA (2012) Quadricuspid pulmonary valve: computed tomography case series and review of relevant literature. J Thorac Imaging 27(6): W171-173.

4. Rajiah P, Nazarian J, Vogelius E, Gilkeson RC (2014) CT and MRI of pulmonary valvular abnormalities. Clin Radiol 69(6): 630-638. 